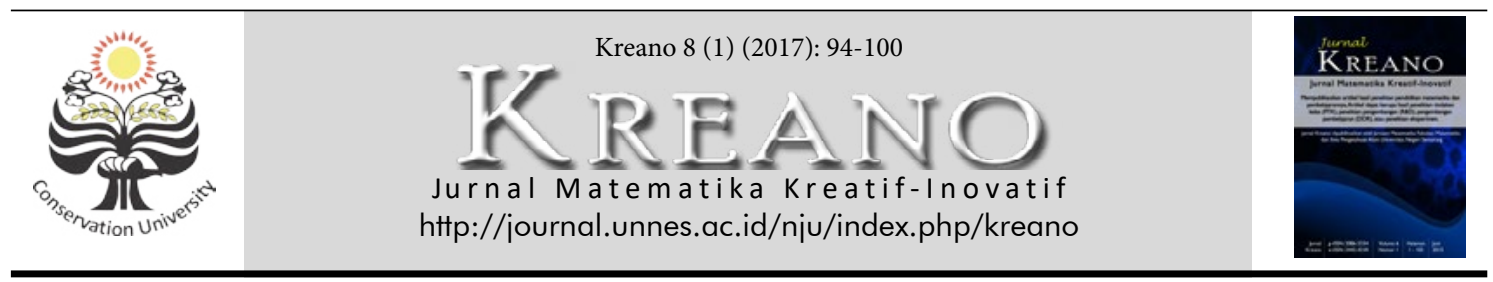

\title{
Pembentukan Konsep Faktorisasi Aljabar Siswa Berkemampuan Tinggi
}

\author{
Muhammad Zuhair Zahid', Imam Sujadi² \\ 'Universitas Negeri Semarang, Jawa Tengah, Indonesia \\ ${ }^{2}$ Universitas Sebelas Maret, Jawa Tengah, Indonesia \\ Email: zuhairzahid@mail.unnes.ac.id',imamsujadi@ymail.com² \\ DOI: http://dx.doi.org/10.15294/kreano.v8i2.7517 \\ Received : October 2016; Accepted: June 2017; Published: June 2017
}

\begin{abstract}
Abstrak
Penelitian kualitatif ini bertujuan untuk mendeskripsikan pembentukan konsep faktorisasi aljabar siswa berkemampuan tinggi dengan sudut pandang Teori APOS. Subjek penelitian adalah siswa SMPN 1 Surakarta berkemampuan tinggi yang dipilih menggunakan purposive sampling. Data dikumpulkan dengan think aloud method. Hasil penelitian menunjukkan bahwa pembentukan konsep faktorisasi aljabar dideskripsikan sebagai berikut. (1) Pada tahap aksi: (a) subjek menyebutkan apa yang ia ketahui dari soal dengan menggunakan gambar dan kata-kata, (b) subjek melakukan operasi pengurangan dengan mengurangkan suku yang memiliki variabel sama. (2) Pada tahap proses: (a) subjek melakukan perkalian bentuk suku dua menggunakan metode FOIL, (b) subjek mengelompokkan suku bervariabel sama secara mental dan tertulis pada saat melakukan penjumlahan trinomial dan perkalian binomial. (3) Pada tahap objek, subjek melakukan faktorisasi menggunakan cara prosedural dan non-prosedural. (4) Pada tahap skema, subjek menjelaskan bahwa faktor-faktor yang ia dapatkan melalui faktorisasi jika dikalikan akan menghasilkan trinomial yang dicari faktornya dan menghubungkan keseluruhan tahap yang ia lalui.
\end{abstract}

\begin{abstract}
The aim of this qualitative research was to describe construction of algebraic factoring concept of high-ability students using APOS theory. The subjects of the research were high-ability students of SMPN 1 Surakarta and have been selected using purposive sampling. Data retrieved using think aloud method. Based on the findings and discussions, it can be concluded as follows. (1) In action stage: (a) subjects presented their knowledge by using pictures and words, and (b) subtracted the simple algebraic form by classifying the algebraic terms which have the same variables. (2) In process stage: (a) subjects multiplied the binomial using FOIL method, and (b) classified the algebraic terms that have same variables mentally and in the written form when they did the trinomial addition and binomial multiplication. (3) In object stage, subjects factorized the trinomial using procedural method and non-procedural method. (4) In schema stage, subject explained that the factor when multiplied by another factor will produce the factored trinomial and linked all the stages to formed a complete concept of algebraic factoring.
\end{abstract}

Keywords: construction of mathematical knowledge; APOS theory; algebraic factoring

\section{PENDAHULUAN}

Tanpa memahami aljabar, kita tidak mampu memahami konsep-konsep yang dipelajari dalam matematika, maupun ilmu selain matematika seperti kimia, fisika, ilmu bumi, ekonomi, bisnis, psikologi, dan ilmu-ilmu lain. Ketidakmampuan memahami konsep dalam bidang tersebut diakibatkan karena aljabar digunakan dalam menuliskan formula dan rumus yang menunnjukkan relasi dua buah objek dalam bidang-bidang ilmu tersebut (Usiskin, 1995). Aljabar sebagai sebuah submateri matematika termasuk materi matematika yang harus dipelajari baik di tingkat menengah, baik di tingkat menengah pertama, maupun tingkat menengah atas. (BSNP, 2006; Permendiknas no. 23 tahun 2006). Pentingnya aljabar dalam matematika tidak diikuti oleh kemampuan siswa Indonesia dalam menyelesaikan soal-soal aljabar. Persentase 
siswa Indonesia yang mampu mengerjakan soal standar TIMMS dalam domain aljabar hanya 22\% (Mullis et al., 2012).

Aljabar adalah salah satu materi matematika yang sulit dipelajari dan merupakan pintu pertama yang dilalui siswa ketika memasuki dunia matematika yang abstrak. Siswa umumnya tidak mengalami kesulitan ketika mempelajari aritmatika, namun mulai mengalami kesulitan ketika mempelajari aljabar. Herscovics \& Linchevski (1994) menyebut bahwa ada gap atau jurang yang harus dilewati oleh siswa ketika akan berpindah dari berpikir aritmatika menuju berpikir aljabar, dan sering kali jurang tersebut sulit dilewati oleh siswa. Banyak siswa yang tidak memiliki basis intuitif memadai ketika mulai belajar aljabar. Siswa kesulitan untuk mengkonstruksi arti dari simbol baru yang mereka pelajari, sehingga mereka akan makin kesulitan melakukan operasi "tak bermakna" yang tak mereka pahami substansinya (Herscovics \& Linchevski, 1994).

Kesulitan seseorang memahami pengetahuan aljabar dibandingkan dengan aritmatika ini terhubung dengan bagaimana pengetahuan aljabar seseorang terbentuk. Pengetahuan matematika (termasuk di dalamnya pengetahuan aljabar) adalah sama dengan pengetahuan lain yang dimiliki manusia, di mana proses pembentukannya memerlukan proses. Beberapa penelitian menunjukkan bahwa pengetahuan disimpan sebagai jaringan konsep dalam otak seseorang dan dikonstruksi dengan membuat hubungan antara informasi baru dan jaringan konseptual atau struktur mental yang sudah ada (Woolfolk \& Margetts, 2013; Carpenter et al, 1988). Pendapat ini mendukung teori konstruktivis Piaget yang berpendapat bahwa proses konstruksi pengetahuan terjadi melalui interaksi dialektis asimilasi dan akomodasi. Perkembangan kognitif anak memegang peranan penting dalam teori konstruktivis Piaget. Dengan memperhatikan teori belajar kognitif, Piaget berfokus pada konstruksi mental dan pengorganisasian objek mental yang terjadi dalam kognisi seseorang. Proses pembentukan objek mental dalam menanggapi suatu realitas terjadi melalui proses asimilasi dan akomodasi. Asimilasi adalah penyesuaian struktur kognitif dengan lingkungan fisik dan akomodasi adalah proses yang menghasilkan mekanisme untuk perkembangan intelektual. Sebelum terjadi akomodasi, pikiran individu berada dalam kondisi seimbang, tetapi dengan asimilasi data baru, terjadi proses mental yang dapat mengakibatkan perubahan dalam struktur organisasi dari skema yang sudah ada. Ide yang dapat diambil dari teori ini adalah penciptaan kondisi yang "sengaja" memunculkan ketidakseimbangan (disequilibrum) dalam struktur kognitif siswa ketika melaksanakan pembelajaran di kelas (Fosnot \& Perry, 1996; Suparno, 1997; Suparno, 2001; Hergenhahn \& Olson, 2009).

Teori epistemologi genetik Piaget kemudian dikembangkan oleh Dubinsky menjadi teori APOS (Action, Process, Object, Scheme). Teori APOS memandang bahwa proses pembentukan pengetahuan matematika seseorang melalui 4 tahap; aksi-proses-objekskema (Dubinsky \& McDonald, 2001). Parraguez \& Oktaç (2010) berhasil menggunakan teori ini untuk menggambarkan pembentukan konsep ruang vektor pada 10 orang mahasiswa yang dipilih. Penelitian ini berhasil mendeskripsikan secara rinci dekomposisi genetik dari materi ruang vektor, sekaligus membagi tahap objek pada tiga buah tingkatan, yakni intraobjek, interobjek, dan transobjek. Transobjek di sini adalah tingkatan objek tertinggi, di mana seseorang mampu menyadari struktur yang saling terkait membentuk objek baru dalam lingkup yang lebih besar.

Stewart \& Thomas (2009) menggunakan Teori APOS untuk mendeskripsikan berbagai masalah yang dialami oleh mahasiswa ketika mengkonstruksi pengetahuan matematika pada mata kuliah Aljabar Linear. Penelitian yang dilakukan oleh keduanya mendapatkan hasil bahwa kegagalan membentuk konsep tertentu (yang berarti ketidakmampuannya mencapai tahap objek) berakibat pada kesulitan seseorang dalam memahami dunia matematika formal, dan akibatnya ia akan cenderung terjebak pada dunia simbolis matematika yang "tanpa makna". Voskoglou (2013) menunjukkan bahwa Teori APOS mampu mendeskripsikan kesulitan-kesulitan yang dialami siswa dalam mengkonstruksi pengetahuan tentang bilangan irasional. Temuan lain dalam penelitian ini adalah bahwa pendekatan ACE (Activities, Classroom Discussion, 
and Exercises) mampu membantu siswa membangun skema kognitif secara efektif.

Penelitian-penelitian yang telah disebutkan menunjukkan bahwa Teori APOS dapat dijadikan alat untuk menggambarkan bagaimana konsep matematika tertentu dibangun dalam kognisi seseorang. Di samping itu, Teori APOS juga dapat dijadikan pisau analisis untuk melihat apakah seorang individu sudah sampai pada tahap tertentu dalam membangun konsep ataukah belum. Seorang peneliti dapat melakukan perbandingan membandingkan dua orang atau lebih siswa, apakah mereka mampu sampai pada tahap tertentu dengan menggunakan indikasi yang dirumuskan berdasarkan Teori APOS. Jika ada dua subjek terindikasi mampu sampai pada konsep matematika tertentu, kemudian salah satu subjek mampu mengambil langkah lanjutan dalam mengeksplorasi konsep tersebut, sementara yang lain tidak, peneliti dapat menjelaskan perbedaan keduanya dengan merujuk pada konstruksi mental subjek yang diteliti, apakah level konstruksi tertentu telah terpenuhi, ataukah belum (Dubinsky \& McDonald, 2001).

Dari latar belakang tersebut, masalah penelitian difokuskan pada konstruksi pengetahuan faktorisasi bentuk aljabar pada siswa berkemampuan tinggi. Tujuan penelitian adalah untuk mendeskripsikan konstruksi pengetahuan faktorisasi bentuk aljabar berdasarkan teori APOS pada siswa kelas VIII SMP berkemampuan tinggi.

\section{METODE}

Penelitian ini bertempat di SMP Negeri 1 Surakarta dan merupakan penelitian kualitatif berjenis studi kasus. Pemilihan SMP Negeri 1 Surakarta sebagai lokasi penelitian dikarenakan sekolah ini mendapat predikat " $\mathrm{A}$ " terkait nilai UAN mata pelajaran matematika yang dicapai siswanya. Predikat yang baik tersebut membuat peneliti berasumsi bahwa keempat tahap Teori APOS akan dapat dicapai oleh siswa, sehingga konstruksi pengetahuan matematika siswa akan bisa dieksplorasi secara maksimal.

Pengambilan data dari subjek menggunakan Think-aloud protocol yang dikembangkan oleh Clayton Lewis. Langkah pengambi- lan data menggunakan think aloud protocol adalah siswa diberikan masalah pada subjek untuk diselesaikan, lalu dalam proses menyelesaikan masalah yang diberikan, siswa diminta untuk mengungkapkan apa yang sedang ia pikirkan secara lisan. Ketika siswa mengungkapkan apa yang ada dalam pikirannya, peneliti merekam kata-kata yang keluar dari mulut siswa menggunakan alat perekam.

Penggunaan Teori APOS dalam penelitian ini meniscayakan adanya indikator alur pemikiran siswa pada materi faktorisasi bentuk aljabar yang diturunkan dari Teori APOS. Indikator dari masing-masing tahap Teori APOS dalam penelitian ini ditunjukkan pada Tabel 1.

Tabel 1. Indikator tahap APOS yang dilalui oleh siswa

\begin{tabular}{|c|c|}
\hline Tahap & Indikator \\
\hline Aksi & $\begin{array}{l}\text { siswa mampu menentukan hal apa } \\
\text { saja yang diketahui dalam soal; dan } \\
\text { siswa mampu menjumlahkan bentuk } \\
\text { aljabar sederhana }\end{array}$ \\
\hline Proses & $\begin{array}{l}\text { siswa mampu menjumlahkan bentuk } \\
\text { trinomial dengan benar; dan siswa } \\
\text { mampu melakukan perkalian bentuk } \\
\text { aljabar antarsuku dua }\end{array}$ \\
\hline Objek & $\begin{array}{l}\text { siswa mampu melakukan faktorisasi } \\
\text { bentuk aljabar }\end{array}$ \\
\hline Skema & $\begin{array}{l}\text { siswa memahami bahwa faktor-fak- } \\
\text { tor yang ia peroleh dari hasil faktori- } \\
\text { sasi jika dikalikan akan menghasilkan } \\
\text { bentuk trinomial aljabar yang ia cari } \\
\text { faktornya; dan siswa mampu menarik } \\
\text { kesimpulan bentuk geometris dari } \\
\text { faktor aljabar yang ia peroleh }\end{array}$ \\
\hline
\end{tabular}

Subjek yang digunakan dalam penelitian ini ialah siswa kelas VIII SMPN 1 Surakarta yang dipilih menggunakan purposive sampling. Subjek yang dipilih adalah siswa yang (1) telah mendapatkan materi faktorisasi bentuk aljabar dalam kegiatan belajar mengajar di sekolah; (2); memiliki kemampuan tinggi; dan (3) mampu mengungkapkan apa yang ia pikirkan dan mengkomunikasikan alur berpikirnya dengan baik.

Seluruh siswa kelas VIII sudah mendapatkan faktorisasi bentuk aljabar di semester pertama, sehingga saat penelitian ini berlangsung, seluruh siswa kelas VIII memungkinkan untuk dipilih sebagai subjek. Selanjutnya selu- 
ruh siswa kelas VIII dibagi menjadi 3 kelompok (tinggi, sedang, dan rendah) berdasarkan hasil ulangan harian materi faktorisasi aljabar. Dari sinilah dipilih kelompok siswa berkemampuan tinggi dengan harapan eksplorasi pengetahuan yang dilakukan dapat secara maksimal menghasilkan deskripsi untuk keempat tahap Teori APOS. Selanjutnya, peneliti berdiskusi dengan guru untuk mencari siswa yang diharapkan mampu mengkomunikasikan alur berpikirnya secara lisan dan tertulis dengan baik. Dari proses terakhir inilah didapatkan dua orang siswa yang memenuhi seluruh kriteria untuk dijadikan subjek.

Penelitian ini menggunakan tes faktorisasi bentuk aljabar yang dikembangkan oleh peneliti. Tes faktorisasi bentuk aljabar disusun sedemikian rupa sehingga alur berpikir siswa saat melakukan faktorisasi bentuk aljabar dapat terdeskripsikan secara maksimal. Data yang diambil adalah proses berpikir siswa yang akan dapat digambarkan dari kata-kata dan tindakan siswa ketika wawancara, catatan lapangan yang disusun, serta hasil pekerjaan siswa ketika mengerjakan soal yang diberikan. Validasi data dalam penelitian ini menggunakan triangulasi data, dengan cara membandingkan data yang diperoleh melalui think aloud pertama dengan data dari think aloud kedua untuk melihat konsistensinya.

Analisis data yang dilakukan meliputi: (1) pembuatan transkrip rekaman siswa ketika mengerjakan soal; (2) penelaahan seluruh data yang didapatkan dari transkrip, catatan lapangan, dan hasil tertulis pekerjaan siswa; (3) reduksi data; (4) pengelompokan data dalam tingkat Aksi, Proses, Objek, dan Skema; (5) analisis dan pendeskripsian proses konstruksi pengetahuan siswa menggunakan Teori APOS; (6) penafsiran data; (7) penarikan kesimpulan dan verifikasi terhadap kesimpulan yang diambil; (8) triangulasi data; (9) analisis terhadap temuan yang ada; dan (10) menulis hasil.

\section{HASIL PENELITIAN DAN PEMBA- HASAN}

Subjek yang dipilih dalam penelitian ini adalah dua orang siswa kelas VIII yang berinisial A (dengan jenis kelamin laki-laki) dan B (berjenis kelamin perempuan). Dari hasil analisis dan deskripsi data dari kedua subjek, didapatkan bahwa subjek penelitian mampu membentuk skema faktorisasi bentuk aljabar melalui aksi, proses, dan objek yang mereka lalui. Subjek juga terlihat mampu menghubungkan dua buah skema yakni skema faktorisasi bentuk aljabar yang mereka bentuk dengan skema bangun datar yang sudah pernah dipelajari di kelas VII. Deskripsi masing-masing tahap dijelaskan sebagai berikut.

\section{Tahap Aksi}

Deskripsi tahap aksi yang dilalui oleh subjek saat mengerjakan tes faktorisasi bentuk aljabar dapat dilihat pada Tabel 2.

Tabel 2. Deskripsi Tahap Aksi oleh Subjek A dan B

\begin{tabular}{ll}
\hline Subjek & Tahap Aksi yang dilalui oleh subjek \\
\hline A & $\begin{array}{l}\text { Subjek A menyebutkan apa saja yang ia } \\
\text { ketahui dari soal secara lisan dan secara } \\
\text { B } \\
\text { tertulis; }\end{array}$ \\
& $\begin{array}{l}\text { Subjek B melakukan penjumlahan } \\
\text { bentuk aljabar sederhana dengan men- } \\
\text { gurangkan masing-masing variabel dan } \\
\text { merubah tanda jika diperlukan. }\end{array}$ \\
\hline
\end{tabular}

Subjek menyebutkan informasi yang ia tangkap dari soal menggunakan gambar atau menggunakan kata-kata yang ia tuliskan pada lembar jawab. Deskripsi dengan berbagai cara ini sesuai dengan pernyataan dari Shadiq \& Widyaiswara (2004) yang menyebutkan bahwa ungkapan mengenai informasi yang ditangkap siswa dari soal dapat dituangkan dalam bentuk gambar, diagram, tabel, ataupun kalimat yang menjadi inti dari soal tersebut. Selain menyebutkan informasi yang ia tangkap dengan gambar dan lembar jawab, pada tahap ini kedua subjek melakukan operasi pengurangan pada bentuk aljabar sederhana. Subjek melakukan pengurangan bentuk aljabar sederhana dengan mengurangkan koofisien dari sebuah variabel dengan koofisien dari variabel yang sama.

\section{Tahap Proses}

Deskripsi tahap proses yang dilalui oleh subjek saat mengerjakan tes faktorisasi bentuk aljabar dapat dilihat pada Tabel 3.

Pada tahap ini, subjek melakukan perkalian bentuk suku dua aljabar dengan meto- 
Tabel 3. Deskripsi Tahap Proses oleh Subjek A dan B

Subjek Tahap Proses yang dilalui oleh subjek

A

1. Subjek $A$ melakukan perkalian dengan tepat. la mengalikan $a_{1} x$ dengan $a_{2} x$ dan $b_{2} y$ serta $b_{1} y$ dengan $a_{2} x$ dan $b_{2} y$. Keempat hasil perkalian dijumlahkan.

2. Subjek A mengurangkan bentuk trinomial aljabar. la mengelompokkan variabel yang sama dan melakukan perubahan tanda di dalam pikirannya.

1. Subjek B melakukan perkalian $a_{1} x$ dengan $a_{2} x$ dan $b_{2} y$ serta $b_{1} y$ dengan $a_{2} x$ dan $b_{2} y$. Keempat hasil perkalian dijumlahkan.

B variabel yang sama secara tertulis, namun ia melakukan keduanya di dalam pikirannya.

de smiley face. Teknik perkalian ini dilakukan dengan urut-urutan: suku pertama dikalikan dengan suku pertama, suku luar dikalikan dengan suku luar, suku dalam dikalikan dengan suku dalam, dan suku terakhir dikalikan dengan suku terakhir. Metode ini adalah satu dari beberapa metode yang dapat digunakan dalam melakukan perkalian aljabar selain splitting method, FOIL method, grid method, dan area method (Chambers \& Timlin, 2013).

Dalam melakukan perkalian bentuk aljabar bersuku dua, subjek melakukan penjumlahan pada bentuk trinomoal yang dihasilkan oleh perkalian yang dilakukan. Dalam melakukan penjumlahan bentuk trinomial kedua subjek melakukan pengelompokan suku bervariabel sama secara mental. Pengelompokan secara mental yang dilakukan oleh kedua subjek sesuai dengan yang dikemukakan Asiala et al. (1996), bahwa tahapan proses dilalui seseorang saat ia mampu dapat merefleksikan, menjelaskan, dan membalikkan langkahlangkah transformasi objek yang sebelumnya dipelajari secara mental tanpa benar-benar menuliskannya pada kertas yang disediakan.

\section{Tahap Objek}

Deskripsi tahap objek yang dilalui oleh subjek saat mengerjakan tes faktorisasi bentuk aljabar dapat dilihat pada Tabel 4 .

Tabel 4. Deskripsi Tahap Objek oleh Subjek A dan $B$

\begin{tabular}{cl}
\hline Subjek & Tahap Objek yang dilalui oleh subjek \\
\hline A & $\begin{array}{l}\text { Subjek A melakukan faktorisasi aljabar } \\
\text { memakai metode AC / prosedural. }\end{array}$ \\
B & $\begin{array}{l}\text { Subjek B melakukan pemfaktoran } \\
\text { dengan cara nonprosedural }\end{array}$ \\
\hline
\end{tabular}

Pada tahap ini, subjek melakukan langkah-langkah faktorisasi bentuk aljabar $a x^{2}+b x y+c y^{2}$ yang berbeda. Subjek A melakukan faktorisasi bentuk aljabar menggunakan cara prosedural, sementara subjek B menggunakan cara nonprosedural. Langkah prosedural yang dilakukan oleh subjek $\mathrm{A}$ dideskripsikan sebagai berikut; (1) subjek melakukan perkalian antara $a$ dan $c$, (2) subjek mengidentifikasi seluruh faktor dari hasil perkalian $a$ dan $c$, (3) subjek mengidentifikasi seluruh faktor dari $a c$, (4) subjek memilih dua di antara seluruh faktor ac yang jika dijumlahkan akan menghasilkan $b$ (sebut saja faktor tersebut adalah $b_{1}$ dan $b_{2}$ ), (5) subjek memanipulasi $b x y$ menjadi $b_{1} x y+b_{2} x y$, (6) subjek mengubah bentuk aljabar $a x^{2}+b x y+c y^{2}$ menjadi $a x^{2}+b_{1} x y+b_{2} x y+c y^{2}$, (7) subjek memberlakukan sifat distribusi perkalian pada penjumlahan pada $\left(a x^{2}+b_{1} x y\right)$ dan $\left(b_{2} x+c y^{2}\right)$, didapatkan $\quad p x\left(\frac{a}{p} x+\frac{b_{1}}{p} y\right)$ dan $q y\left(\frac{b_{2}}{q} x+\frac{c}{q} y\right)$, (8) subjek memeriksa apakah $\frac{a}{p}=\frac{b_{2}}{q}$ dan $\frac{b_{1}}{p}=\frac{c}{q}$, (9) digunakan sifat distributif perkalian pada penjumlahan, 
sehingga didapat $(p x+q y)\left(\frac{a}{p} x+\frac{b_{1}}{p} y\right)$ atau $(p x+q y)\left(\frac{b_{2}}{q} x+\frac{c}{q} y\right)$ sebagai faktor
yang dicari. Adapun Subjek B dalam melakukan faktorisasi bentuk aljabar menggunakan cara nonprosedural dengan rincian; (1) subjek mendaftar seluruh faktor dari $a$ dan $c$, (2) diambil dua buah faktor dari $a$ (misal $a_{i}$ dan $a_{n-i}$ ) dan $c$ (misal $c_{i}$ dan $\left.c_{n-i}\right)$, (3) subjek mengalikan $a_{i}$ dengan $c_{m-j}$, dan mengalikan $a_{n-i}$ dengan $c_{j}$, (3) hasil perkalian ( $a_{i} c_{m-j}$ dan $\left.a_{n-i} c_{j}\right)$ dijumlahkan dan diperiksa hasilnya, apakah sama dengan $b$ atau tidak, (4) Jika $a_{i} c_{m-j}+a_{n-i} c_{j}=b$, proses faktorisasi selesai, dan disimpulkan bahwa faktor yang dicari adalah $\left(a_{i} x+c_{m-j} y\right)$ dan $\left(a_{n-i} x+c_{j} y\right)$, (5) jika $a_{i} c_{m-j}+a_{n-i} c_{j} \neq b$ maka langkah nomor (2) diulang sampai didapatkan faktor dari $a$ dan $c$ yang memenuhi.

Saat melakukan faktorisasi aljabar, subjek melakukan penguraian terhadap proses yang ia lakukan. Proses yang dimaksud adalah proses perkalian dua buah bentuk aljabar binomial, di mana pada tahap faktorisasi aljabar dilakukan penguraian bentuk trinomial menjadi dua buah binomial yang tadinya di- kalikan. Dua proses yang dilakukan oleh subjek $A$ dan subjek $B$ berbeda satu sama lain. Proses yang dilakukan oleh Subjek A disebut AC method (Steinmetz \& Cunningham, 1983; Erisman, 1986; Zahid et al., 2014), subjek B menggunakan cara cepat yang berbeda dengan cara prosedural. Secara umum, cara yang dipakai oleh subjek B masuk dalam kategori cara non-prosedural. (Setiawan \& Widdiharto, 2009; Rahardjo, 2006; Zahid et al., 2014).

\section{Tahap Skema}

Deskripsi tahap skema yang dilalui oleh subjek saat mengerjakan tes faktorisasi bentuk aljabar dapat dilihat pada Tabel 5 .

Kedua subjek mendeskripsikan secara jelas bahwa mereka mampu menghubungkan proses dan objek dari materi faktorisasi aljabar dengan skema lain yang telah dipelajari sebelumnya, dalam hal ini ialah skema bangun datar (khususnya persegi dan persegi panjang).

\section{PENUTUP}

\section{Simpulan}

Konstruksi pengetahuan matematika siswa hasil penelitian ini dideskripsikan sebagai berikut. (1) Pada tahap aksi, subjek menyebutkan apa yang ia ketahui dari soal dengan menggunakan gambar, ataupun menggunakan kata-kata yang ia tuliskan pada lembar jawab. Subjek pada tahap aksi melakukan

Tabel 5. Deskripsi Tahap Skema oleh Subjek A dan B

\begin{tabular}{cc}
\hline Subjek & \multicolumn{1}{c}{ Tahapan Skema yang dilalui oleh subjek } \\
\hline A & 1. Subjek A menjelaskan bahwa faktor yang ia dapat dari langkah faktorisasi jika \\
& dikalikan akan menghasilkan bentuk aljabar yang ia faktorkan. la menjelaskan ja- \\
& wabannya secara lisan dan tertulis. \\
& 2. Subjek A menghubungkan hasil pemfaktoran yang ia lakukan dengan konsep \\
& persegi dikarenakan panjang dan lebarnya sama panjang. \\
B $\quad$ 1. Subjek B menjelaskan bahwa faktor yang ia dapat dari langkah faktorisasi jika & dikalikan akan menghasilkan bentuk aljabar yang ia faktorkan. la menjelaskan ja- \\
& wabannya secara lisan. \\
& 2. Subjek B menghubungkan faktor yang ia dapatkan dalam langkah faktorisasi \\
& dengan bentuk persegi, dikarenakan panjang dan lebarnya memiliki ukuran yang \\
& sama. \\
3. Subjek menjelaskan bahwa salah satu bentuk yang lain adalah persegi panjang \\
dikarenakan ukuran panjang dan lebarnya berbeda.
\end{tabular}


operasi pengurangan dengan jalan mengurangkan suku yang memiliki variabel sama. (2) Pada tahap proses, subjek melakukan perkalian bentuk suku dua menggunakan metode FOIL. Terkait dengan penjumlahan trinomial dan perkalian binomial, subjek mengelompokkan suku yang bervariabel sama dengan dua macam cara; secara mental dan mengelompokkan secara tertulis pada lembar jawab. (3) Pada tahap objek, subjek melakukan faktorisasi dengan menggunakan cara prosedural dan non-prosedural. (4) Pada tahap skema, subjek menjelaskan bahwa faktor-faktor yang ia dapatkan melalui faktorisasi jika dikalikan akan menghasilkan bentuk aljabar yang dicari faktornya. Subjek menghubungkan proses dan objek yang ia lalui sehingga membentuk pemahaman yang utuh mengenai konsep faktor aljabar.

Saran dari hasil penelitian ini dipaparkan sebagai berikut. (1) Dalam menyusun rencana pembelajaran, guru matematika di tingkat SMP dapat mempertimbangkan bagaimana sebuah konsep matematika dapat terbentuk. (2) Peneliti lanjutan dapat melakukan penelitian pada topik matematika selain faktorisasi bentuk aljabar. (3) Peneliti lanjutan hendaknya dapat menggunakan teori konstruksi pengetahuan selain teori APOS sebagai pisau analisis, sehingga diperoleh karakteristik konstruksi pengetahuan siswa yang lebih variatif. (4) Peneliti lanjutan dapat menggunakan tinjauan tertentu untuk menemukan karakteristik konstruksi pengetahuan siswa agar deskripsi konstruksi pengetahuan matematika menjadi lebih lengkap.

\section{DAFTAR PUSTAKA}

Asiala, M., Brown, A., DeFries, D.J., Dubinsky, E., Mathews, D., \& Thomas, K. (1996). "A Framework for research and curriculum development in undergraduate mathematics education". Research in Collegiate Mathematics Education 2(3), CBMS Issues in Mathematics Education, pp. 1-23.

BSNP. (2006). Standar Isi untuk Satuan Pendidikan Dasar dan Menengah: Standar Kompetensi dan Kompetensi Dasar SMP/MTs. Jakarta: Badan Standar Nasional Pendidikan.

Carpenter, T. P., Fennema, E., Peterson, P. L., \& Carey, D. A. (1988). Teachers' pedagogical content knowledge of students' problem solving in elementary arithmetic. Journal for research in mathematics education, 385-401.

Dubinsky, E. \& McDonald, M.A. (2001). APOS: a constructivist theory of learning in undergraduate mathematics education research. In Holton, D. (Ed.), The Teaching and Learning of Mathematics at University Level: an ICMI Study. pp. 273280. Netherlands: Kluwer Academic Publishers.

Erisman, R. J. (1986). Factoring Trinomials: $a x^{2}+b x+c$. The Mathematics Teacher, 79(2), 124-129

Fosnot, C. T., \& Perry, R. S. (1996). Constructivism: A psychological theory of learning. Constructivism: Theory, perspectives, and practice, 2, 8-33.

Hergenhahn, B.R. \& Olson, M.H., (2009). Theories of Learning. Edisi Ketujuh. Terj. Wibowo, T.S., Jakarta: Kencana.

Herscovics, N., \& Linchevski, L. (1994). A cognitive gap between arithmetic and algebra. Educational studies in mathematics, 27(1), 59-78.

Mullis, I.V.S., Martin, M.O., Foy, P. \& Arora, A. TIMSS: 2011 International Results in Mathematics, USA: TIMSS \& PIRLS International Study Center.?

Parraguez, M., \& Oktaç, A. (2010). Construction of the vector space concept from the viewpoint of APOS theory. Linear Algebra and its Applications, 432(8), 2112-2124.

Peraturan Menteri Pendidikan Nasional No. 23 Tahun 2006 tentang Standar Kompetensi Lulusan untuk Satuan Pendidikan Dasar dan Menengah.

Rahardjo, M., (2006). Solusi masalah pemfaktoran bentuk kuadrat. Buletin Limas, no. 17, Desember 2006. pp. 30-34. Yogyakarta: P3G Matematika.

Setiawan \& Widdiharto, R. (2009). Kapita Selekta Pembelajaran Aljabar Kelas VIII SMP. Yogyakarta: P4TK Matematika.

Shadiq, F., \& Widyaiswara. (2004). Pemecahan Masalah, Penalaran, dan Komunikasi: Bahan Diklat Instruktur Matematika SMA. Yogyakarta: $P_{3} G$ Matematika

Steinmetz, A. M., \& Cunningham, S. (1983). Factoring Trinomials: Trial and Error? Never!. The Mathematics Teacher, 76(1), 28-30

Stewart, S., \& Thomas, M. O. J. (2009). Linear algebra snapshots through APOS and embodied, symbolic and formal worlds of mathematical thinking. In Crossing divides: Proceedings of the 32nd annual conference of the Mathematics Education Research Group of Australasia (Vol. 2, pp. 507514). Palmerstone North, NZ: MERGA.

Suparno, P. (1997). Filsafat Konstruktivisme dalam Pendidikan. Yogyakarta: Kanisius.

Suparno, P. (2001). Teori Perkembangan Kognitif Jean Piaget. Yogyakarta: Kanisius.

Usiskin, Z. (1995). Why is algebra important to learn. American Educator, 19(1), 30-37

Voskoglou, M. G. (2013). An application of the APOS/ ACE approach in teaching the irrational numbers. Journal of Mathematical Sciences and Mathematics Education, 8(1), 30-47

Woolfolk, A., \& Margetts, K. (2013). Educational psychology. Frenchs Forest: Pearson Education Australia

Zahid, M. Z., Sujadi, I., Saputro, D.R.S. (2014). Eksplorasi Konstruksi Pengetahuan Matematika Siswa Kelas VIII SMP Negeri 1 Surakarta Menggunakan Teori Action, Process, Object, Scheme (APOS) pada Materi Pokok Faktorisasi Bentuk Aljabar. Jurnal Pembelajaran Matematika, 7(2): 714-726 